\title{
Tribute to Professor Dr. Guy Sebag
}

(C) Springer-Verlag Berlin Heidelberg 2015

While a new European Managing Editor is now taking up office at Pediatric Radiology after an interim period following the sudden unexpected death of the past European Managing Editor Professor Dr. Guy Sebag on 28th November 2014, Springer would like to look back and recognize Professor Sebag's commitment and achievements for the journal.

After serving as member of the journal's editorial board, Guy joined the editorial team in 2003 as Assistant Editor to Steve Chapman, European Managing Editor, and the American Managing Editor Walter Berdon later followed by Tom Slovis.

In 2009, Guy succeeded Steve Chapman as European Managing Editor and started shaping the journal in close and intimate cooperation with the American Managing Editor Tom Slovis and later with Peter Strouse. Over the years, he worked closely and trustfully with his Assistant Editors Veronica Donoghue, Derek Roebuck, Øystein Olsen and Annie Paterson in a strong European editorial team.

Pediatric Radiology flourished during Guy's editorship. In cooperation with the American Editorial team, he developed Pediatric Radiology as the primary journal of the international pediatric radiology community at multiple levels and adapted it to the ever changing needs of the pediatric radiology community. The diversity, quality and quantity of the content, the strength of editorial team and process as well as close cooperation with the major pediatric radiology societies worldwide were the main focuses of his editorship. Major achievements include the acquisition of highly attractive minisymposia article collections and special issues on important topics as well as the launch of new and timely types of journal content including the educational series 'Fellow Rounds' and the research series 'Research Forum'. Between 2009 and 2014, the journal's content increased steadily. At the same time, the impact factor increased from 1.186 to 1.651 , and Pediatric Radiology ranked within the top 15 most highly downloaded medical journals at Springer.

Guy's era saw a number of further important developments. In 2005/2006, Pediatric Radiology became the official journal of the Asian and Oceanic Society for Pediatric Radiology (AOSPR) as well as of the Latin American Society for Pediatric Radiology (SLARP), respectively, and Guy acted as liaison between the editorial team and the AOSPR. In 2012, the American and European editorial teams initiated regular Pediatric Radiology journal workshops on how to write and review articles at the annual meetings of the European Society of Paediatric Radiology (ESPR) and the Society for Pediatric Radiology (SPR).

From the publishing perspective, Guy's term of office fell into an exciting as well as challenging time, the transition from print to electronic tools and media at all levels of the publishing process from manuscript submission, peer review and publication up to content presentation, marketing, usage and dissemination.

Guy's enthusiasm and excellent work, together with his high level of commitment and dedication to the journal made these numerous developments and achievements possible. At Springer, we will remember him as a charming and warm person with a fine sense of humor. His unexpected death came as a shock to all of us, and we would like to acknowledge our high respect and our recognition for all his invaluable contributions to our journal Pediatric Radiology. 